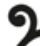

\title{
DESIGN DE SERVIÇOS NO SETOR PÚBLICO: ESTUDO DE CASO DA LEI DE LIBERAÇÃO DE EVENTOS DA PREFEITURA DE JOINVILLE - SC
}

\author{
Guilherme Hobi \\ Universidade Positivo \\ guilherme.hobi@gmail.com \\ Gisele Raulik-Murphy \\ Universidade Positivo / Duco \\ gisele@ducontact.com \\ Sara Sanchez de Christiano \\ Universidade Positivo / Duco \\ sara@ducontact.com
}

Resumo: Ao analisar o cenário dos serviços públicos brasileiro, é possível notar que habitualmente, organismos públicos não levam em consideração as necessidades de seus contribuintes. Por outro lado, o design de serviços apresenta-se como uma abordagem centrada no usuário, ou seja, com a premissa principal de tomar o indivíduo como foco, buscando entender suas características, necessidades e desejos projetando soluções pautadas nestas constatações. Com o intuito de compreender de que forma a abordagem do design de serviços pode ser aplicada no setor público, o artigo apresenta o estudo de caso da reformulação da Lei de Liberação de Eventos da Prefeitura de Joinville, do estado de Santa Catarina.

Palavras-chave: design de serviços, setor público, lei, Joinville.

\begin{abstract}
Analyzing the Brazilian Public Sector, is clearly Government Agencies usually does not consider your contributors needs in their actions. On the other side, the service design methodology presents your user centered approach, applying as the main premise the user as focus, seeking figure out their characteristics, needs and wants to design solutions guided by these findings. In order to understand how Service Design approach can be applied to the Public Sector, this article presents a case study from Joinville City Council. Joinville is a city on the State of Santa Catarina, Brazil. The City Council was applying successfully the service design methodology to recreate the law for allowing events to happen.
\end{abstract}

Keywords: service design, public sector, law, Joinville. 


\section{INTRODUÇÃO}

Ao analisar o cenário dos serviços públicos brasileiro, é possível notar que habitualmente, organismos públicos não levam em consideração as necessidades de seus contribuintes. Por outro lado, o design de serviços apresenta-se como uma abordagem centrada no usuário, ou seja, com a premissa principal de tomar o indivíduo como foco, buscando entender suas características, necessidades e desejos projetando soluções pautadas nestas constatações. O objetivo desta abordagem é proporcionar serviços úteis, utilizáveis e desejáveis para os clientes e eficazes e eficientes para as organizações (MORITZ, MAGER \& COUNCIL, 2014).

A presente pesquisa tem por objetivo compreender de que forma a abordagem do design de serviços pode ser aplicada no setor público, aportando seus aspectos mais característicos a um sistema carente das mesmas.

Para iniciar a compreensão das formas que a abordagem do design de serviços pode ser aplicada no setor público, foi realizado o levantamento teórico de conceitos do design de serviços, assim como referências de sua aplicação em governos. Com o objetivo de evidenciar na prática o uso do design de serviços pelo setor público, por meio de um exemplo real de impacto positivo, foi realizado o presente estudo de caso.

Um exemplo de sucesso da aplicação do design de serviços pelo setor público, é o caso da lei de liberação de eventos de Joinville. Onde servidores públicos aplicaram o método e as ferramentas do design, utilizando uma visão sistêmica e centrada no cidadão, para reestruturar a lei de forma que o processo se tornasse menos burocrático, tanto aos produtores de evento quanto aos funcionários da prefeitura.

Neste artigo é apresentado como a prefeitura utilizou o design de serviços para reestruturar esta lei. Como conclusão, são apresentadas as premissas do design de serviços identificadas no levantamento teórico e como elas, aplicadas ao setor público, conferem vantagens aos governos, após a constatação realizada mediante o estudo de caso.

\section{DESENVOLVIMENTO}

Design de serviços ainda é um tema recente no Brasil, com poucos profissionais especializados e, portanto, ainda pouco conhecido no mercado. Neste contexto, o desenvolvimento de estudos de caso é de grande relevância à medida que contribuem para a divulgação e compreensão do tema.

Este estudo foi desenvolvido nos meses de setembro e novembro de 2015, através de dados primários, levantados junto à Prefeitura de Joinville, principalmente com o diretor da Secretaria de Integração e Desenvolvimento Econômico (SIDE), Ari Vieira Junior, e dados secundários publicados.

\subsection{Referencial Teórico}

\subsubsection{Design de serviços}

O design de serviços como disciplina, surgiu em meados dos anos 1990 na Köln International School of Design (KISD). Segundo Birgit Mager, professora pioneira na KISD, "o design de serviços coreografa processos, tecnologias e interações dentro de sistemas complexos, a fim de cocriar valor para os stakeholders" (MAGER, 2015). 
Serviços são intangíveis, não podem ser armazenados ou ser de propriedade, o consumo acontece ao mesmo tempo em que são produzidos e se tratam de experiências complexas que ocorrem ao longo do tempo. Para estudá-los, é necessária uma nova abordagem multidisciplinar da expertise do design, envolvendo uma sequência de pontos de contatos: o design de serviços (MORITZ, 2005).

De modo geral, o design de serviços é uma abordagem centrada no usuário, que exige uma visão holística e cocriativa, envolvendo usuários, profissionais de áreas relacionadas e colaboradores no processo. Moritz, Mager, \& Council (2014), defendem que seu objetivo é criar serviços úteis, utilizáveis, desejáveis para os clientes, eficazes e eficientes para as organizações.

Com base na Fig.1, é possível observar um mapa mental, desenvolvido a partir do pensamento de alguns dos principais autores da área, Birgit Mager, Bill Hollins, Marc Stickdorn, Stefan Mortiz e Service Design Network, uma rede fundada e organizada por profissionais e entusiastas do design de serviços.

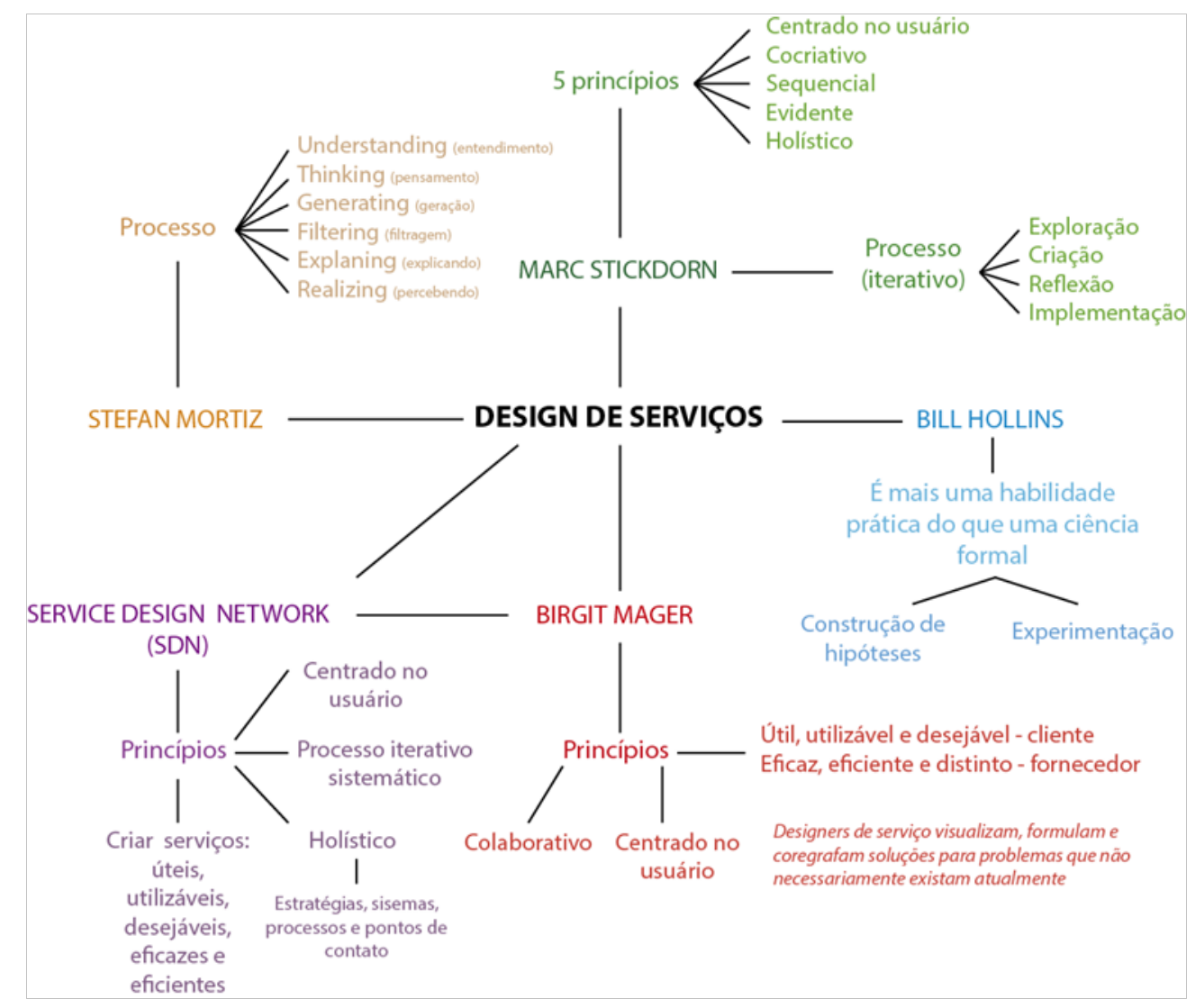

Figura 1 - Mapa mental dos principais autores sobre design de serviços FONTE: Autores

Após análise dos pensamentos, é possível concluir que o design de serviços é uma abordagem centrada no usuário, cocriativa e colaborativa. Além disso, é notável que exige uma visão holística do processo e ambiente. No processo, o número de etapas pode variar, mas habitualmente segue o mesmo trajeto, devendo ser iterativo, começar com uma imersão no problema, passando pela geração de ideias e protótipos até chegar à sua implementação. Comum a todos, no design de serviços, é imprescindível o foco no usuário durante todo o processo. Desta maneira, objetiva-se 
criar serviços mais competitivos, desejáveis e sem falhas, que aumentam diretamente a satisfação dos clientes além de tornar as organizações mais eficazes e eficientes (WHICHER, SWIATEK, \& CAWOOD, 2013).

Com base na conclusão de estudos de casos feito por Steen, Manschot e Koning (2013), é possível relatar três tipos de benefícios que a abordagem do design de serviços traz: benefícios para o próprio projeto, como a melhoria do processo; benefícios para os clientes do serviço ou usuários, melhor relação entre as reais necessidades dos clientes e usuários com a oferta do serviço, o que gera uma melhor experiência e maior satisfação; benefícios para a organização, tais como melhorar a criatividade, foco em clientes ou usuários, melhora a relação entre prestadores do serviço e clientes, entre outros.

Por isso, o design de serviços mostra-se como uma alternativa eficaz e viável para as autoridades públicas desenvolverem ou aprimorarem serviços que atendam às necessidades dos cidadãos (WICHER, SWIATEK \& CAWOOD, 2013).

\subsubsection{Design de serviços no setor público}

Frente aos problemas que comumente o setor público enfrenta, como desperdício de dinheiro público, falta de transparência e falta de proximidade com o cidadão, alguns países passaram a utilizar conceitos de design para melhorar o desempenho deste setor. Utilizando-o como ferramenta estratégica para renovação e crescimento econômico, desde a criação de novas políticas até na prestação dos serviços públicos.

A Comissão Europeia reconhece o design de serviços como um dos principais impulsionadores da inovação dos serviços, inovação social e inovação centrada no usuário (WHICHER, SWIATEK e CAWOOD, 2013).

As principais vantagens da utilização do design para a realização de projetos de serviços públicos são: encontrar as reais necessidades, poupar dinheiro público, humanizar os serviços e envolver os cidadãos (COMISSION, 2013).

O design pode ser aplicado no setor público em diversos níveis. Desde a utilização para projetos de serviços isolados, até a utilização em níveis organizacionais. O SEE Platform (2013) propôs a Escada do design no setor público, como uma ferramenta para diagnosticar diferentes níveis de uso de design pelos governos.

No primeiro nível da Escada do design no setor público o design é aplicado para problemas pontuais. Nesta categoria, projetos de design acontecem casualmente e o processo de design não está incorporado nas organizações.

O segundo nível considera o design como uma habilidade do governo. Aqui, os servidores públicos além de participarem do processo de design, utilizam o design sem o apoio de designers. Muitas técnicas de design podem ser passadas facilmente para não-designers, gerando resultados eficientes durante operações do dia-a-dia.

No terceiro e último nível o design é utilizado para a criação de políticas. Nesta etapa o design é utilizado em nível estratégico e organizacional pelos indivíduos do governo com poder de tomada de decisões. A lógica da aplicação do design neste nível é sólida, pois atende às necessidades dos decisores políticos. Entre essas necessidades encontram-se a união de processos, desde a criação de políticas até a sua implementação; a redução de riscos através da realização de protótipos de baixo custo; a obtenção da visão geral do sistema; e desatar nichos de departamentos, incluindo pessoas externas. 


\section{A APLICAÇÃO DE DESIGN DE SERVIÇOS NA PREFEITURA DE JONVILLE}

Servidores públicos da cidade de Joinville, no estado de Santa Catarina, vêm utilizando o design como ferramenta para solucionar problemas complexos em suas secretarias. O objetivo deste artigo é mostrar como este processo aconteceu e aumentar o entendimento de como o setor público utiliza o design de serviços.

\subsection{0 cenário}

Um dos maiores problemas observados pela Prefeitura de Joinville, foi que no que tange à prestação dos serviços públicos, o poder público considera o cidadão como um contribuinte, não levando em consideração suas necessidades. Outro problema encontrado foi que o poder público, recorrentemente, não visualiza a totalidade de um problema e com isso, ao tentar resolver partes de um problema, acaba gerando mais problemas adiante. Esta prática faz despender muito tempo buscando resolver problemas que o próprio poder público criou, sendo que poderia ser evitado utilizando um modelo de visão mais ampla, comenta Junior (2015).

Como alternativa para mudar este cenário, a Prefeitura de Joinville passou a tomar todas as suas decisões colocando o cidadão em primeiro plano, ao invés da estrutura pública como normalmente acontece. "A cidade tem o DNA da inovação, e a Prefeitura faz parte disso. Está tentando se reinventar, assim como as empresas, seguindo uma tendência de mercado" enfatiza o Secretário de Integração e Desenvolvimento Econômico na SIDE, Danilo Conti (PREFEITURA DE JOINVILLE, 2015). O Gerente da SIDE, Ari Vieira Junior comenta que estão trabalhando com foco no cidadão e nas suas necessidades. "Se existem tarefas que não são inerentes ao cidadão, não é ele que deve resolver e sim o município. Então a função de procurar ferramentas para solucionar um problema é o próprio município" Junior (2015). Ari foi convidado a integrar a equipe da prefeitura para resolver dois problemas pontuais: abertura de empresas e liberação de eventos.

\subsection{Lei de liberação de eventos}

Quando assumiu seu cargo na Prefeitura de Joinville, Ari Vieira Junior acompanhara há mais de 12 anos que os indivíduos do segmento de eventos enfrentavam diversas barreiras para conseguir o alvará de liberação de evento. Era recorrente a reclamação, por parte dos envolvidos e interessados, que realizar eventos em Joinville tratava-se de uma tarefa complexa.

Em gestão anterior, como solução, foi desenvolvido um software para automatizar o processo de liberação do alvará. No entanto, não houve análise do problema, tampouco qualquer alteração no processo em si, apenas a automatização do mesmo. A gestão que assumiu em seguida não deu andamento ao uso do software, pois identificou imediatamente que o software não apresentara a solução do problema, atuando simploriamente como uma automatização da burocracia.

Por outro lado, foi verificado que uma legislação antiga não vinha sendo aplicada, e caso fosse, inviabilizaria todos os eventos em Joinville. Com isso, o Prefeito deu à SIDE um prazo de 30 dias para que, junto com uma equipe a designar, resolvesse um problema que não havia sido resolvido nos últimos 12 anos. Neste momento, Ari Vieira Júnior defendeu o uso da metodologia do design, pois estava muito satisfeito com os resultados que o design trouxe para a sua empresa de eventos, após contratar uma consultoria especializada. “Em vez de procurarmos leis já existentes e tentar 
adaptar para Joinville, fizemos algo totalmente novo, partindo do zero, com base nas necessidades locais" Junior (2015). A partir da metodologia do design thinking aplicado à serviços, sob moderação do Ari Vieira Junior e as ferramentas de design cedidas pelo consultor Michel Winkler, iniciou-se o projeto para criar a nova lei de liberação de eventos (lei 407).

Desde seu início, o projeto contou com uma equipe multidisciplinar. Em um primeiro momento, foi formada uma equipe interna da prefeitura a fim de verificar o seu entendimento da situação. Entre os integrantes estavam advogados da Secretaria da Fazenda, com o conhecimento tributário; Ari, como moderador do processo e produtor de eventos; Douglas Hoffman, da Fundação Turística apresentando o interesse do município em atrair o turismo por meio de eventos; e Marcus Faust, na época Coordenador de um espaço público para eventos.

Após entender a situação, foi encontrado que o maior problema era o fato de que normalmente as leis são construídas complementando leis já escritas e vigentes. Esta prática faz com que se gere mais uma lei sem formar um conjunto único, dificultando o entendimento do cidadão e até mesmo a sua correta execução. Com isto em mente, a primeira constatação foi a necessidade de filtrar etapas realmente necessárias para aquela lei específica funcionar, ou seja, definir seus pilares (principais pontos que sustentam a lei). A partir de então, foram envolvidas outras pessoas no processo, tais como produtores de eventos; representantes da Vigilância Sanitária; representantes da Câmara de Dirigentes e Lojistas (CDL); a equipe de assessores do atual Vereador Manoel Bento; além de representantes do Corpo de Bombeiros e da Polícia Civil.

$\mathrm{Na}$ fase de pesquisa ou imersão no problema, os produtores de eventos destacaram os pontos críticos do processo: dúvida sobre o processo devido à falta de clareza e subjetividade da lei; descentralização, pois o produtor de eventos deveria ir a diferentes pontos da cidade para levar ou buscar documentos, onde os horários de funcionamento de alguns locais não condiziam; duplicidade de cobranças; necessidade de tirar alvará para um mesmo local duas ou até três vezes na semana; a linearidade do processo, o que impedia de dar entrada em vários órgãos ao mesmo tempo (por exemplo Polícia Civil e Bombeiros), pois era necessário dar entrada em um de cada vez.

Com o levantamento dos pontos críticos do problema, iniciou-se a fase de ideação, onde os integrantes da equipe de trabalho interna desenharam a condição atual da lei e seu cenário ideal. "As pessoas expressam muitas coisas através de um simples desenho, assim conseguimos entender o que cada pessoa pensava" Junior (2015). Com isso, foi possível identificar que o processo se apresentava confuso e sua idealização deveria ter: entrada e saída única; legislação agrupada através de formulário único e acompanhamento online.

Partindo da necessidade de um sistema de entrada e saída única, a equipe realizou um levantamento de soluções em outros contextos e localizou um sistema já utilizado na gestão pública que funciona desta forma, os portos de navios. Neste sistema, todos os navios que desejam aportar passam por uma entrada e saída única e além disso, é utilizado um sistema de cores (verde, vermelho e preto) que indicam se o navio está regularizado ou não para aportar. As mesmas cores apontam o processo a ser realizado para a liberação do direito de aportar o navio.

Apropriando-se deste conceito, em fase de desenvolvimento da solução, a equipe de trabalho da Prefeitura de Joinville definiu o uso das três cores para 
diferenciar a situação do local de eventos em relação ao seu alvará de liberação e para guiar o indivíduo no processo de obtenção do alvará. Foi definida a cor verde para apontar quando o estabelecimento já possui alvará válido do município e da Polícia Civil para a atividade de eventos. A cor preta foi aplicada para indicar quando o local já possui alvará válido do município para a atividade de eventos e não possui da Policia Civil. Por fim, a cor vermelha foi definida para assinalar que o local não possui alvará válido do município para a atividade de eventos e também não possui da Policia Civil. Com estas cores definidas, o indivíduo, ao iniciar seu processo de liberação, identifica sua cor de acordo com seu status e esta mesma cor indica qual é o processo que deverá realizar para obter a liberação.

Definida a lógica do sistema, foram definidos os pilares que sustentariam essa lei, ou seja, apenas os itens essenciais para que um local possa ter seu alvará para liberação de evento. Os quatro pilares definidos foram: o local, sendo que sem um espaço físico o evento não acontece; o público, pois um evento só acontece com pessoas; o motivo pelo qual está acontecendo; e a segurança, seja ela física, de ordem, jurídica, entre outras.

Estes pilares também funcionaram como um filtro, uma vez que todas as ações e etapas do processo deveriam encaixar-se nos pilares. Os itens que não se encaixavam, foram descartados, evitando etapas desnecessárias.

Durante o projeto, também foi analisada a lei anterior visando reorganizá-la e levando em consideração o usuário como centro, ou seja, colocando-o como foco e analisando o processo sob suas perspectivas, necessidades e desejos. Para isso, foi utilizada a ferramenta do design de serviços chamada Jornada do Usuário. Por meio desta ferramenta foi possível identificar que pontos cruciais de definição do processo encontrava-se no final do processo de liberação, fazendo com que o indivíduo passe por diversas etapas para constatar que o estabelecimento não estava apto para receber eventos. Portanto, foi realizada uma análise para averiguar se estes pontos cruciais poderiam estar no início do processo, evitando que o usuário passe por outras etapas dissociadas destes pontos cruciais sem necessidade.

Com o processo reorganizado e consolidado, como evidencia a Fig. 2, o indivíduo encontra logo no início do processo os pontos cruciais como "Alvará da PMJ", "Alvará da Polícia Civil" e "Aprovado por consulta prévia Seinfra". Sendo assim, o usuário poderá informar-se se está apto a continuar no processo para a liberação de eventos e qual caminho ou processo deverá seguir, por meio do desenho do fluxo e cores nele indicadas.

Com o redesenho da lei, foi possível eliminar ou rearranjar funções que estavam duplicadas e até mesmo desnecessárias, que os diversos órgãos realizavam. Desta forma, as funções foram reorganizadas, a Prefeitura deixou de cobrar o que não competia a ela e concentrou-se no que cabia a ela exigir, sendo os alvarás. Da mesma forma, o poder de fiscalização passou a verificar os eventos, cumprindo com sua função de fiscalizar e não mais exigir do usuário a emissão de diversos documentos que foram identificados como desnecessários.

O processo anterior exigia do indivíduo cerca de 20 etapas que por vezes, ao final delas, teria seu alvará negado. Por isso, a ordem das etapas foi alterada e com a reestruturação da lei são necessárias 5 etapas. "Antes o produtor passava 5 dias em função da regularização, agora se tudo estiver de acordo, ele pode receber o alvará na hora" Junior (2015). 


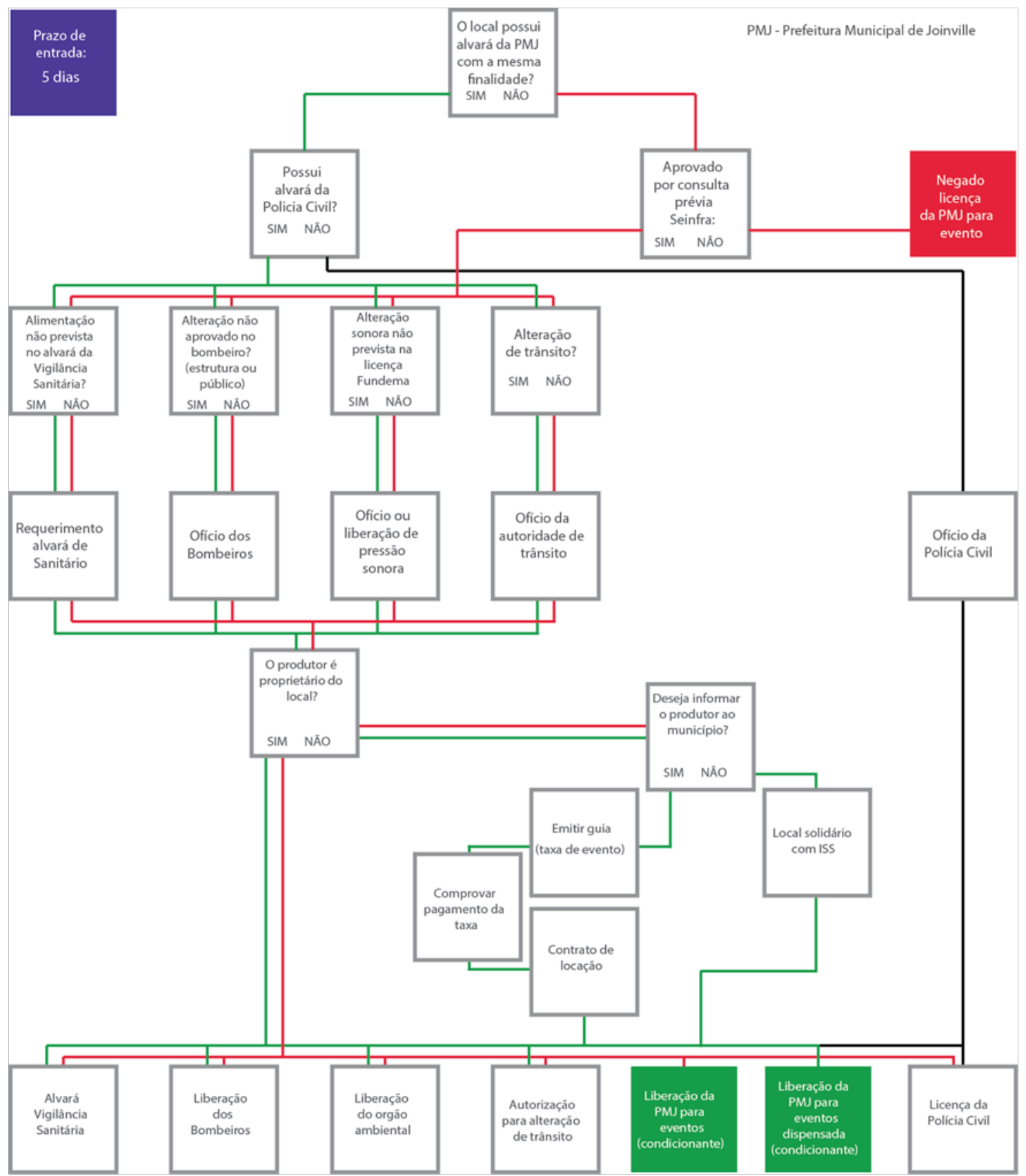

FIGURA 2 - Processo da lei de liberação de eventos FONTE: Autor

A multa antiga apresentava o valor de cerca de $\mathrm{R} \$ 230,00$, tornando mais vantajoso ao indivíduo arriscar a irregularidade do que regularizar seu evento, uma vez que o complexo e demorado processo exigia grande esforço do produtor. Na nova lei, a multa foi estipulada em cerca de 10 mil reais (50 UPMs) e o processo para a regularização tornou-se mais fácil de entender o que precisa ser feito e rápido. Diante deste panorama, tornou-se mais vantajoso para o indivíduo estar regularizado do que arriscar a irregularidade.

No processo anterior, o cidadão deveria consultar um compilado de cerca de 200 páginas em que constava todas as leis anteriores que tinham alguma referência sobre eventos. Em 2015 a lei foi consolidada em 6 páginas com o detalhamento do procedimento e documentos necessários para a requisição da liberação do alvará para 
eventos (JUNIOR, 2015). Até o fim desta presente pesquisa, o projeto estava sendo sistematizado para que o cidadão pudesse fazer todo o processo online, com assinatura digital e com a possibilidade de anexar os documentos necessários.

$\mathrm{Na}$ Fig. 3 é possível observar um resumo das diferenças entre a lei antiga e a nova lei de liberação de eventos, reformulada por meio do processo do design de serviços. Torna-se clara a diferença, principalmente no que tange às ações necessárias para o usuário que deseja obter o alvará. Para a Prefeitura de Joinville, o grande ganho apresenta-se na simplificação de sua função com a desburocratização do processo.

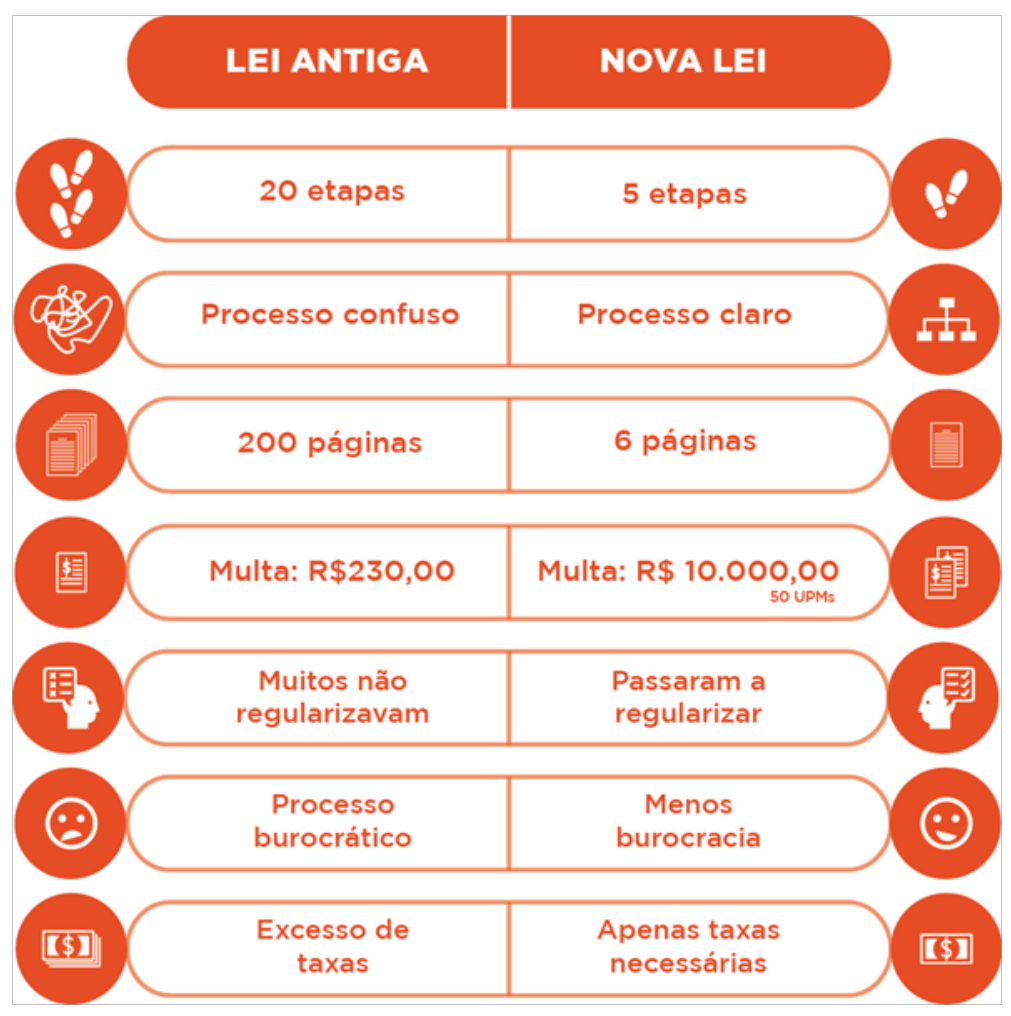

FIGURA 3 - Antes e depois da lei de liberação de eventos FONTE: Autores

Em decorrência do uso do design para a reformulação da lei de liberação de eventos, a Prefeitura de Joinville enxergou no design uma oportunidade para resolver problemas complexos de sua estrutura e ao mesmo tempo colocar o cidadão como centro de seus projetos. Por meio dessa abordagem, a Prefeitura passou a desburocratizar processos constantemente, criar novas leis e melhorar a experiência de seus cidadãos ao utilizarem os serviços da Prefeitura. O olhar atento às reais necessidades de sua população junto com o uso de novas metodologias, reforça sua identidade de cidade inovadora.

O diretor executivo da SAP, Filipe Schuur, explica que o design oferece uma metodologia capaz de gerar um entendimento do problema, gerar alternativas, prototipar e implementar soluções. Também comenta que o uso intensivo de ferramentas visuais é um grande diferencial no ambiente burocrático. Para ele, a visualização permite ampliar o entendimento sobre o assunto e rapidamente criar uma narrativa consistente sobre o problema e a solução, possibilitando uma ação rápida. (PREFEITURA DE JOINVILLE, 2015). 
Outras secretarias da Prefeitura de Joinville, como a Secretaria de Assistência Social (SAS), a Secretaria de Administração e Planejamento (SAP) e a Vigilância Sanitária também passaram a utilizar os conceitos de design. Na SIDE, além dos projetos citados, a metodologia foi utilizada para estabelecer o modelo de negócios da secretaria. Na SAS, foi utilizado para reestruturar as atividades e criar um modelo de incubação. A SAP, vem utilizando o design desde 2013 para conceber e testar, ou prototipar, o funcionamento de unidades da administração municipal, entre elas, as subprefeituras.

A continuidade do uso da metodologia do design no setor público é um grande desafio a ser enfrentado pela Prefeitura, pois caso os profissionais de carreira na prefeitura não incorporem o uso desta metodologia como uma habilidade interna, com a troca de gestão, seu uso pode ser encerrado. Adiantando-se a esta possibilidade, a Prefeitura de Joinville já possui alguns profissionais de carreira que absorveram a metodologia e a utilizam em projetos dentro de suas secretarias.

\section{CONCLUSÃO}

Este estudo de caso presta-se para confirmar o que foi constatado no levantamento e análise do referencial teórico. Como conclusão, apresenta-se uma série de vantagens de utilizar o design de serviços no setor público, resumidos à Fig. 4.

Tendo como premissa da metodologia do design de serviços o foco no usuário, a primeira vantagem diz respeito à relação entre cidadão e governo, que com a possibilidade de colocar efetivamente os cidadãos como foco dos projetos, envolvendo-os nos processos de criação e melhora das soluções públicas, é possível atingir a aproximação do cidadão com o governo. Com esta aproximação é possível gerar uma relação positiva entre cidadão e governo, pois além do cidadão sentir-se incluído ao participar do processo, o governo logra gerar soluções adequadas, suprindo as necessidades e satisfazendo os desejos dos cidadãos.

Outra característica clara do design de serviços é o envolvimento de stakeholders e a realização de projetos com equipes multidisciplinares. Com o estudo de caso, evidencia-se que esta característica apresenta vantagens para a geração de soluções do setor público pois ao envolver os stakeholders é possível considerar as necessidades de todos os envolvidos. Por outro lado, a variedade de conhecimento das pessoas presentes na equipe confere a possibilidade de gerar soluções inusitadas para a resolução de um problema, criadas a partir da análise de como outras áreas solucionam um problema de natureza similar ou até mesmo por meio de analogias.

A visão holística do problema e do processo é outro aspecto do design de serviços que foi possível comprovar sua vantagem de utilização pelo setor público. Encarar os problemas e processos de maneira abrangente, considerando de forma integral todos os itens que o envolvem, permitem a geração de soluções efetivas, ou seja, soluções que funcionem de fato, sem ações redundantes e desnecessárias à função principal e sem que uma solução gere novos problemas.

Outro princípio do design de serviços é o uso das diversas ferramentas de design, e entre elas, as que oferecem maior vantagem ao setor público são as de prototipação. A prototipação permite ao setor público o teste de ideias e soluções a baixo custo, a modo de verificar e validar seu funcionamento. Com esta oportunidade é possível realizar ajustes na solução antes de sua implementação final e desta forma, 
o dinheiro público é usado com cautela, realizando investimentos aos poucos e com maior assertividade.

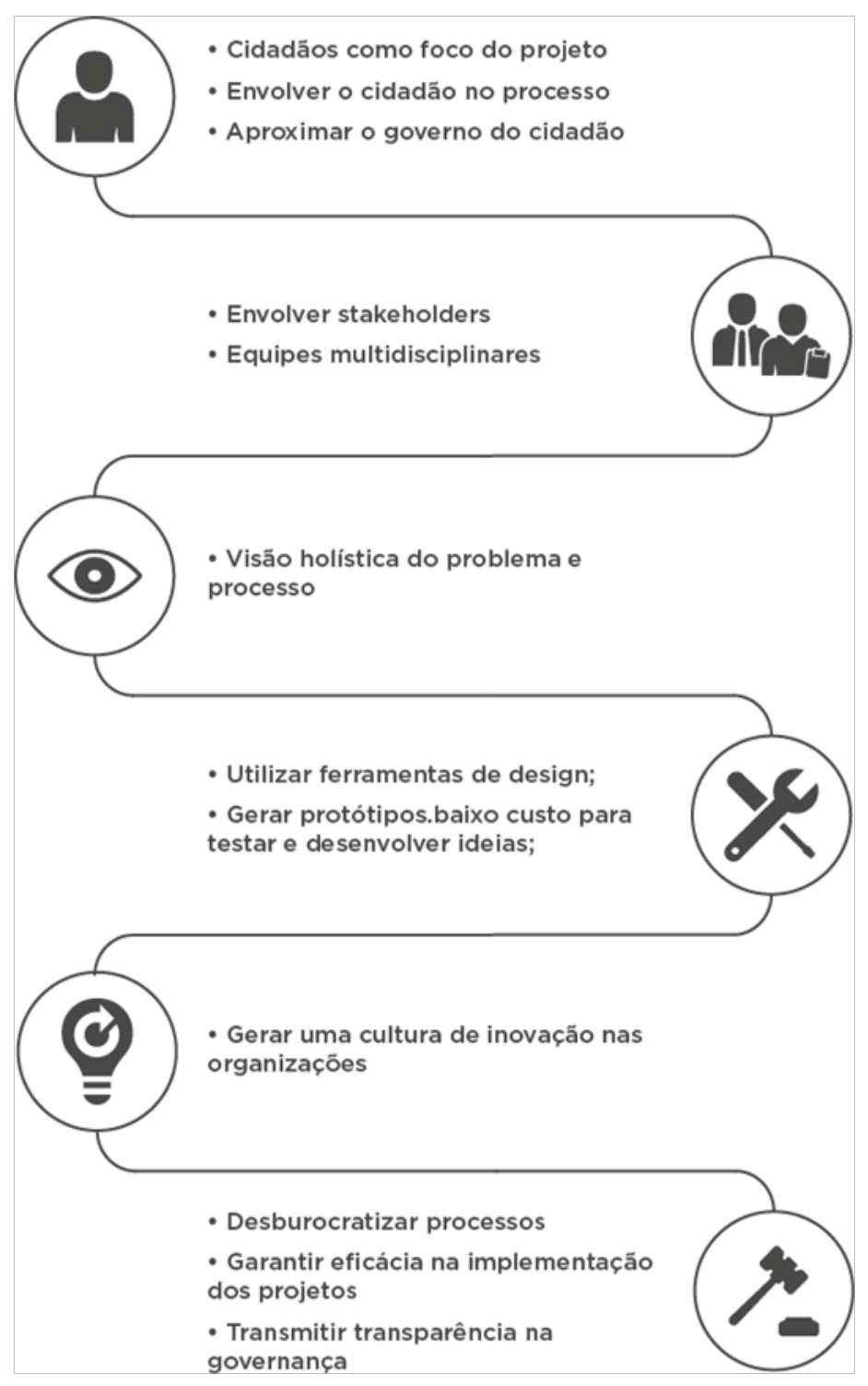

FIGURA 4 - Vantagens de utilizar o design de serviços no setor público FONTE: Autores

Por fim, a prática constante do design de serviços no setor público tornando-a uma habilidade interna, é capaz de gerar uma cultura de inovação nas organizações, invertendo valores e modos de funcionamento atuais, apresentando como maiores vantagens e benefícios a desburocratização de processos, a garantia de eficácia na implementação dos projetos e soluções, assim como a transmissão de transparência na governança. Isso mostra que o design de serviços é uma alternativa viável para o Brasil, pois não exige novas tecnologias e grandes investimentos, apenas remodelar processos e a forma de pensar. 


\section{REFERÊNCIAS}

COMISSION, D. Restarting Britain 2: Design \& Public Services. Policy Connect. Londres. 2013.

JUNIOR, A. V. Prefeitura Municipal de Joinville. Joinville, 29 setembro 2015. Entrevista a Guilherme Hobi

MAGER, B. Service Design. In: ERLHOFF, M.; MARSHALL, T. Design Dictionary, Perspectives on Design Terminology. Basel: Birkhäuser, 2008.

MAGER, B. Service Design Network. Service Design Network. Disponível na internet por http em: <http://www.service-design-network.org/birgit-mager-president-ofsdnon-20-years-of-service-design/>. Acesso em 6 abril 2015;

MORITZ, S. Service Design: pratical acess to an evolving field. [S.I.]: Köln International School of Design, University of Applied Sciences Cologne, 2005.

MORITZ, S.; MAGER, B.; COUNCIL, U. D. Definição: O design de serviços como abordagem interdisciplinar. In: STICKDORN, M.; SCHNEIDER, J.; ORGS. Isto é Design Thinking de Serviços / Marc Stickdorn, Jakob Schneider e coautores. Porto Alegre: Bookman, 2014. p. 33.

PREFEITURA DE JOINVILLE. Prefeitura de Joinville, 2015. Disponível na internet por http

em:<https://www.joinville.sc.gov.br/noticia/10789Prefeitura+de+Joinville+adota+met odologia+inovadora+para+agilizar+processos.html>. Acesso em 8 set. 2015.

SACO, R. M.; GONÇALVES, A. P. Service Design: An Appraisal. Design Management Review, 2008.

SEE PLATFORM. Design for Public Good. SEE Platform. Londres. 2013.

STEEN, M.; MANSCHOT, M.; KONING, N. D. Benefits of Co-design in Service Design Projects. International Journal of Design, v. 5, p. 53-60, 2011.

WHICHER, A.; SWIATEK, P.; CAWOOD, G. An Overview of Service Design for the Private and Public Sectors. Cardiff. 2013. 